\title{
Los ideólogos contra Sófocles
}

\author{
OCTAVIO A. SEQUEIROS \\ Ex. Univ. Nac. de La Plata \\ República Argentina
}

\begin{abstract}
RESUMO: A interpretação de Édipo Rei resulta tão contraditória quanto os princípios, raras vezes confessados com franqueza, dos quais parte cada estudioso convicto de expôr com "objetividade". Assim, deparamo-nos com um Édipo imoral, outro ainda marionete do destino e um terceiro, mero pretexto de um jogo estético pós-modernista; há múltiplas variantes. Apresento, historicamente, as principais interpretações globais deste século, pretendendo desmascarar a cortina ideológica de cada uma e a maior ou menor coincidência com o texto de Sófocles, ao qual retornam os melhores críticos que seguem Aristóteles, sempre o mais jovem de todos.
\end{abstract}

PALAVRAS-CHAVE: Sófocles, Édipo Rei, interpretações.

\section{El Problema}

René Guenon ha dicho varias veces que las obras tradicionales se vuelven cada día más incomprensibles para los hombres actuales; sin compartir las ideas de Guenon ni la validez general de esta afirmación, creo que ella es sorprendentemente aplicable a la crítica contemporánea más prestigiosa sobre Edipo rey.

En la VI Reunión de 1991 en Belo Horizonte y en otros trabajos he expuesto la crítica psicoanalítica con esta perspectiva. Ahora me referiré a algunos aspectos claves de la filológica.

Como es sabido la crítica puede emitir los juicios más contradictorios e inverosímiles sobre una misma obra con la buena conciencia que da el hábito de las ciencias del "espíritu". Edipo Rey no es precisamente una excepción, de modo que para ubicarnos en las interpretaciones contemporáneas hay que imitar modestamente a Dios y ordenar el caos primigenio con una cierta coherencia. De ello ya se encargó E. R. Dodds en 1966 al analizar, siguiendo la huella de Wilamowitz (1927), las falsas interpretaciones de nuestra obra vinculadas a un tema clave: la acción divina y su justificación. Vale la pena sintetizarlo.

El 90\% de los estudiantes de letras clásicas de Oxford -el 10\% restante no se define o no se expresa de modo inteligible- se adhiere a una de estas tres interpretaciones probadamente erróneas:

1) la mayor parte cree que Edipo sufre lo que se merece por su mal carácter o su vana pretensión de eludir los oráculos, es decir por "un defecto moral" como se traduce la palabra amartia del cap. XIII de la Poética aristotélica. Pero en contra nos encontramos con que amartia no significa "falla moral" en ese texto según requiere la "perversidad de la crítica moralizante", sino 
sólo error intelectual sin ninguna responsabilidad subjetiva. Por otra parte el oráculo es anterior a cualquier falencia moral de Edipo, pues aún no había nacido.

2) Edipo Rey sería una "tragedia de destino" donde el hombre es un títere de los dioses y carece de libre voluntad, v.g. Freud entre muchos otros. Tesis anacrónica pues el determinismo es un problema posterior del mundo helenístico. Homero y Sófocles no pensaban así y de modo explícito los versos 1230 ss. hablan de ciertos actos libres: nada menos que de todos los que ocurren en la escena....Pero aún los hechos conocidos desde antiguo por los dioses, según el criterio antiguo, permiten nuestra libre voluntad, y "esto puede no satisfacer al filósofo analítico, pero parece haber satisfecho al hombre común de todas las épocas"; así lo comprobamos en el Evangelio cuando Cristo anuncia la triple negación de Pedro antes de que cante el gallo, sin que el primer Papa abdique de su responsabilidad personal. Además aquí no son los dioses la causa inmediata de la caída de Edipo - el oráculo no dijo que debía descubrir el secreto- sino su coraje y decisión de salvar a Tebas y conocer la verdad. Edipo no se ciega por creerse moralmente culpable, sino por horror ante la vileza objetiva, un sentimiento que el mundo cristiano desconoce.

3) La tesis esteticista: Sófocles sería un "artista puro" y como tal no le interesaría un rábano justificar a los dioses, meros instrumentos o aparato de la intriga. Así Waldock (1966) niega todo significado o mensaje y sólo nos quedaría "el terror de la coincidencia". Dodds (1966) simpatiza con este criterio opuesto a las tesis moralistas, pero observa que según Sófocles si bien los dioses no son justos en el sentido humano, deben ser reverenciados como lo prueba el verso 895, tan famoso, que Dodds parafrasea así: "Si Atenas pierde su fe en la religión, si la opinión del iluminismo prevalece, ¿qué sentido tiene el drama trágico, que existe como una parte del servicio de los dioses? Puede decirse que la rápida decadencia de la tragedia en la cuarta centuria ha proporcionado una respuesta a esta pregunta." Edipo Rey se escribió al parecer durante una guerra en la que el oráculo de Delfos era pro espartano, lo que posibilitó la crítica de Eurípides, pero Sófocles lo defiende.

El profesor de Yale Michael O’Brien (1968), que publicó una buena selección de Edipo Rey integrada por veintisiete autores, se enfrenta también al tercer error señalado por Dodds, observa que si aceptamos la tesis de un Sófocles "poeta puro" sin vestigios de "filósofo", su obra carece de contenido para la humanidad y Edipo se convierte en un mero personaje individual que no genera o representa un aspecto de la naturaleza humana o un tipo genérico.

Pero una vez rechazada esta tesis hay que descifrar el supuesto mensaje y Edipo se convierte en otra esfinge pues los eruditos, como siempre, están en absoluto desacuerdo. Aún aceptando como universalmente válida en Grecia la idea de que el poeta es el educador del pueblo (Jaeger W., 1933; Webster T.B.L., 1936) no es posible que Edipo represente a Pericles (Ehrenberg V., 1954), ni que simbolice a Atenas (Knox B., 1964). Sheppard A.(1947) ha tratado de demostrar que Edipo Rey nos enseña una virtud muy griega, la sofrosunh, cuyo significado o mejor cuyo "campo semántico" por no ser menos científico que nadie, incluye conceptos como moderación, modestia, prudencia, temperancia, conciencia de los límites personales y de la especie humana en general. Según Sheppard resulta que el modelo sería el piadoso y moderado Creón que precisamente al final discute con Edipo sobre la sofrosunh. Pero esto es absurdo porque tanto Creón como los restantes personajes carecen del brillo, el coraje, el sentido de la responsabilidad y la verdad, como para convertirse en modelos de virtud alguna. Sófocles no es el Platón de Cármides y no ha querido enseñarnos por medio de Creón.

Como solución O'Brien propone esta distinción: Edipo representa la vida humana en general, pero ese sentido universal no es reductible a un sistema coherente de valores morales. Claro que nuestro autor exagera en provecho propio pues nadie ha pretendido ver en Edipo Rey un sistema de valores, sino captar el sentido de la obra, lo menos que se le puede pedir a un crítico. Veamos su solución: Sófocles está influido por el iluminismo del siglo V, perceptible en la 
conciencia del lenguaje y en ciertas actitudes (cf. Knox), v.g. estaba difundida la concepción humanística de que el conocimiento del hombre, especialmente el tecnológico y científico, constituía su principal protección contra el desastre.

Es ésta la actitud de Edipo antes de la caída; otra idea clave de difusión general era el famoso consejo apolíneo "conócete a ti mismo", o sea, conoce tus limitaciones frente a los

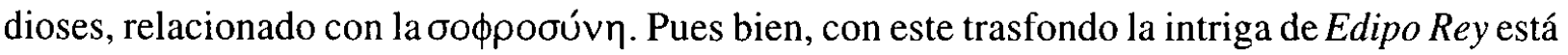
sustentada en el acto de la inteligencia de un hombre, Edipo, entre cuyas cualidades es precisamente la inteligencia la única ( $\mathrm{O}^{`} \mathrm{Brien}$ se olvida de la voluntad) que alcanza un resultado superior: "El héroe es un hombre cuya auto estimación está enraizada en el orgullo de la inteligencia." Aquí O'Brien olvida también que Edipo valora por sobre todo la salvación de la ciudad, como veremos, lo que contradice su tesis.

En síntesis, según este autor, Edipo sería pues para Sófocles un modelo universal educativo, un "paradigma" como expresamente dicen los versos 1196 ss., consistente en que "un hombre compite en agudeza con los dioses." Lamentablemente esto último resulta un emplasto, producto del nietzcheanismo difuso en la inteligencia contemporánea, que no está en Sófocles. Posteriormente el mismo O'Brien matiza un poco este criterio explicando que en realidad, Sófocles transforma un antiguo tema mítico -el hombre que compite con Dios y pierde- en una antítesis entre el conocimiento como poder y el autoconocimiento, adaptándolo de este modo al iluminismo del siglo V.

Dejaré a un lado otras corrientes de la crítica, por ejemplo la estructuralista de Tycho von Wilamowitz, y expondré sólo algunos de los principales representantes de la corriente "existencialista"; se denomina así porque destaca la experiencia íntima de Edipo, su presunta humillación y desconcierto ante los dioses, modelo de todo sufrimiento y de la naturaleza del hombre. Estos críticos por lo general juegan su partido aparte contra Dios, así que el de Sófocles es utilizado como pretexto para exponer su propia y desesperanzada concepción del mundo.

Los caracteres comunes más salientes de esta posición, aunque no siempre se encuentren juntos en un autor, son: 1) la perversidad o irracionalidad de Dios; 2) el rechazo de la culpa trágica heredada, aquí la pederastia de Layo, cuya sola mención parece un atentado a los derechos humanos; a esto se alude con el llamado "análisis trágico" de Schiller; 3) Edipo convertido a veces en antihéroe por su falta de libertad moral o en un cierto "superman" idealista;4) dificultades para encontrarle algún sentido coherente al texto de Sófocles; 5) despolitización de toda la obra y en especial de Edipo.

\section{Los Ideólogos}

Así para Pohlenz (Pohlenz M., 1930) nos encontramos ante un hombre sin culpa ni conocimiento, pues la naturaleza hiere a un hombre "de carne y hueso como nosotros", "un hombre que sólo quiere el bien y es digno de amor"(p.220). Hay algo de autocomplacencia pietista y de sermón laico en esta conclusión.

Weinstock (Weinstock, H., 1931) posee el mismo trasfondo filosófico que Reinhardt, el monstruo sagrado de la crítica de Sófocles, pero escribe en lenguaje más directo y llega de antemano a las mismas consecuencias intelectuales; es un hegeliano asumido y sistemático de modo que, a diferencia de otros congéneres, acepta la culpa heredada y el pecado de Layo constituye el destino de Edipo: el que arroja la primera piedra a un estanque sereno es responsable hasta de la última onda; el dios panteísta que está dentro del mundo y de cada uno conoce al lanzador de la piedra (Layo) y también su última consecuencia, a saber : el pobre Edipo que actúa inconscientemente. Sólo Dios es síntesis, en cambio el hombre sólo posee un mero presentimiento del abismo cuyo real conocimiento le impediría la acción. Los oráculos equivalen a la mala 
conciencia del actuante y quien los elude destruye la sacralidad, lo único que puede sostenerlo, y se derrumba, como Yocasta, creyendo librarse de la angustia (p.205 ss.)

La última consecuencia está expresada en el verso 1186 que expresaría la renuncia a la acción, pues este Sófocles mistificado nos viene a enseñar que aún sirviendo a la poliV el hombre permanece en su finitud e ignorancia. Según Hegel el Estado es la culminación del Espíritu Absoluto, pero Weinstock le es infiel y en su ensayo está explícitamente promovida la despolitización de Edipo.

Una parodia de Reinhardt (Reinhardt K., 1933) en lenguaje popular argentino podría expresarse así: hay que salvar las apariencias porque no somos nada; por lo menos de esa manera actúa Yocasta, pero no Edipo que se pregunta 1) ¿quién soy? 2) ¿cuál es mi ser?. En realidad no me parece que Edipo se pregunte por su "Ser" en el sentido metafísico que le da Reinhardt con el objeto de explicar nuestro drama sobre la base de la dialéctica apariencia-Ser, donde se pondrá a prueba el "Ser" del individuo.

Sigamos con este crítico alemán: paradójicamente la humildad reflexiva convierte a Edipo en un héroe, en un ser absoluto pleno de orgullo y entregado a su propio valor, en suma todo un héroe hegeliano del "Espíritu"; esta "humildad" es muy diferente de la cristiana nos dice Reinhardt, pero se cuida de definirla y ni falta que hace pues semejante Edipo se parece previsiblemente al superhombre idealista heredado de Nietzsche.

Reinhardt es agudo en muchas de sus observaciones, pero su estilo pretensioso y pedante está al servicio de una verdadera mistificación, ya que lo menos que debe exigirse a un crítico es precisión y claridad..

Untersteiner (Untersteiner M., 1935), mezcla de italiano y alemán, pertenece a la "Italia hegeliana", lo que se descubre muy pronto; esta tragedia encarnaría el proceso de realización y aniquilamiento del individuo; el hombre se diviniza cuando por un instante alcanza a conocer la verdad gracias al diálogo interior.

Nuestro profesor tiene que aplicarle este remiendo al pobre Edipo y por ello no vacila en afirmar comentando los v. 30-33: "Edipo es sentido por el sacerdote, por el sacerdote intenta negar que su rey sea tal para no mancharse de impiedad" (op. cit., p.157).

Edipo no es un hombre qualumque como el suscripto, convencido ingenuamente de que el bien y el mal son potencias dotadas de voluntad y, un espíritu vulgar "que afirma y cree en un Dios fuera de sî" (op. cit., p. 163 y 170-171), todo lo contrario, dentro de él (el Edipo de Untersteiner) se revela la potencia irresistible del movimiento dialéctico con autonomía respecto de todo juicio humano o divino.

En el éxodo Edipo se condena a "una vida que sea sólo pensamiento", renunciando "al orgullo de la personalidad" (op. cit. p.206), para alcanzar "una espiritualidad total".

Kitto (Kitto H.D.F., 1939), utiliza criterios no menos idealistas, pero al negar la culpa de Layo, obligatoriamente tiene que poner en duda la existencia de un orden cósmico, concepción absolutamente ajena a Sófocles, aunque de inmediato, sin preocupase por la lógica más elemental introduce el concepto de üßpıৎ que supone dicho orden.

Los argentinos, aunque estamos en el tercer mundo, tenemos una intérprete revolucionaria que escribe en ambiente al final de la última gran guerra. Según ella (Lida, M. R., 1944) Sófocles tiene "el ideal artístico de la humanidad esencial (p.138), pues "se ocupa exclusivamente del hombre" (p. 19) y, lo que es peor, "de la conciencia que asoma a la revelación de la subconciencia" (p.152), Feuerbach casi textual.

Una vez extraviado en los laberintos gnósticos ese Sófocles puede imitar a María Rosa Lida y darse el lujo de ignorar la culpa heredada limitándose a describir la perversión que lo rodea: todo el orden natural le es hostil y mucho más el orden social de por sí arbitrario. A ese incomprendido le falta sólo el fusil para ponerse al lado del Cristo guerrillero de la teología de la 
liberación.

Alguien tiene que tener la culpa de todo eso: Dios por supuesto (p.202 y 263); a partir de esta cómoda premisa Lida concluye en "el profundo pesimismo de Sófocles" (p.193), cuya fe a pesar de los oráculos no es tan ingenua como la de Pindaro.

Para mayor complicación M. R. Lida es freudiana y en consecuencia también su hijo Edipo, perversamente inclinado hacia su madre y sus hijas: "Con franqueza única Sófocles ha presentado los toques morbosos que integran el carácter de todo hombre normal"(p. 142).

Turolla (Turolla E., 1948) es por demás contradictorio. Los dioses son injustos y calculadores al detalle, "determinismo religioso" (p.82); Edipo es "fantasma y vana sombra" (p.86); Sófocles un "apologeta" (evidentemente un insulto según Turolla) de "la voluntad del Oscuro" (p. 99), que usa del mito para escandalizar a los delicados turollas, "hombres comunes, hijos del iluminismo" (p.100); por suerte, cuando parece que Sófocles va a odiar definitivamente a Edipo, al final "llora con nosotros" -es decir con Turolla- (p. 109) ante este "símbolo del dolor humano". El existencialismo sentimental y autocomplaciente no puede con Sófocles.

Por fin Whitman (Whitman C.H., 1951) es un hombre tajante como lo demuestra este título de un capítulo: Maldad irracional: Edipo Rey, maldad que constituye "la estructura de la divinidad" (p. 122) o sea la esencia de Dios, si queremos expresarnos de modo inteligible, así que la desesperación y el terror es la clave de todo; incluida su crítica, agreguemos.

Por lo demás ataca con razón a Reinhardt, porque su esquema neutraliza la absoluta amargura del drama, la injusticia de los dioses y la inocencia moral de Edipo. En resumen Sófocles era medio escéptico al igual que sus contemporáneos y Edipo es el héroe del "autoconocimiento", término que usa, como casi toda la crítica, de modo ambigüo, pues no se trata en nuestra obra del conocimiento de sí mismo, de la interioridad humana que en Edipo no varía, sino de su situación objetiva, social y religiosa.

En síntesis la "excelencia" humana posee "su propia divinidad" que suele no bastar "para afirmarse a sí misma frente a la maldad irracional que desciende sin plan ni justicia y desde donde nadie conoce" (p.143); estamos frente a la revelación "del destino perverso del hombre" (idem) y

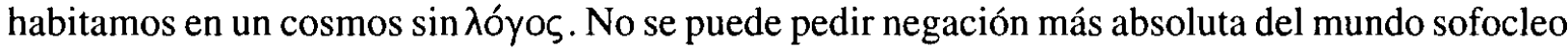
y griego en general, aunque la obra de Whitman resulte atrayente por su vigor y sobre todo por la acidez para con sus camaradas.

\section{Peregrinación a las fuentes}

Por más aciertos y observaciones parciales que debamos agradecer a estos eruditos, sostengo que ellos abandonan en lo fundamental la serena consideración del texto y se dejan arrastrar por una perspectiva ideológica modernista, tipo New Age, que desvirtúa sus esfuerzos.

De allí que fuera necesaria una vuelta a Sófocles, a una intelección ponderada de su poema. En este itinerario a las fuentes me parecen de especial importancia Eilhard Schlesinger (1950), Ignacio Errandonea (1958) y Antonio Maddalena (1963), cuyas contribuciones no puedo explicar.

En cambio he elegido a Franz Egermann (Egermann F., 1957) como contraposición a la crítica existencialista, porque su obra es menos accesible a nuestro medio y por la crudeza de sus apreciaciones que lo han convertido en ...

\section{El crítico maldito}

Egermann goza de la peor fama entre los especialistas más prestigiosos, y no es para menos, porque nuestro autor ha despedazado con gran humor y minucia los criterios fundamentales 
de la crítica moderna, no sólo sobre Edipo Rey, sino sobre Sófocles y la tragedia en general.

Con increíble sentido común, Edipo vuelve a ser el que era, es decir un héroe con toda la barba; el héroe encarna la más alta virtud $(\alpha \rho \varepsilon \tau \eta)$, y ésta resulta imposible sin la libre elección del peligro y el desprecio de la utilidad, las ventajas personales y la vida.

El héroe a su vez no se define por el dolor ni se reduce a él, por agudo e insoluble que sea, ni al sufrimiento, la caída o la peripecia desde la más alta felicidad, la muerte la ubriV o exceso, sino por esa libre decisión de defender el valor supremo, la justicia en coincidencia con Platón y Aristóteles que culminan una línea, la más noble, permanente desde el Aquiles de Homero.

En consecuencia la grandeza de todo héroe en Esquilo o Sófocles, pero muy especialmente en Edipo, es incompatible con su supuesta ceguera espiritual o mental; no existe ese invento nefasto que la crítica denominó "ceguera trágica", términos absolutamente antitéticos: no hay héroe sin clarividencia. La mentida ceguera trágica de Edipo suele fundarse sobre todo en la interpretación pretendidamente literal de los v. 747 ss. y 955 ss, de la cual resulta un Edipo disminuído mental que no comprendería lo que ya había dicho Yocasta con excesiva claridad.(p. 18). Edipo oculta su conocimiento, por lo menos no lo manifiesta a gritos, de modo que lo escuchen estos críticos, para impedir que la gente común a su vez le oculte la realidad, y con serenidad sobrehumana busca la verdad sin concesiones para sí mismo. Se saca los ojos por pudor (v. 1371 ss.) y no para ofrecernos un "símbolo" de la ceguera espiritual que nunca tuvo. Ya en el v. 914 es evidente que sabe todo sin ayuda de nadie (p. 95).

Ese Edipo que se aviva de golpe al final, modelo de inanidad humana, de estupidez y vanagloria, sería para Sófocles un personaje de comedia (p.82), pues, según el testimonio de Aristóteles, que nuestros filólogos dejan escandalosamente a un lado (Poética, 1460 b 36 s), presentaba a los hombres tal como debían ser (dei einai), o sea que sus héroes son modelos de virtud y no payasos o títeres, son activos y no pasivos, son clarividentes y no cegatones, inteligentes en vez de testarudos o imbéciles.

Dicho criterio además era moneda corriente en toda su época, como lo prueban Herodoto, Demóstenes, Platón, Aristóteles y luego Séneca cuyo Edipo, en ese aspecto, parafrasea al de Sófocles; lo prueba también Aristófanes y la historia real, especialmente a partir de Maratón, donde se inspiró Sófocles, que no era un trasnochado reaccionario, supuesto inventor de no sabemos qué ignoto código de caballería vigente antes de Homero, según lo imaginan los más eminentes comentaristas. Con semejante tesis la crítica, casi siempre estetizante, pretende escindir a Sófocles de su Atenas, de su vida, pero lo único que consiguen es rellenarlo con mala filosofía del siglo XX.

Desde Reinhardt, la filología ha sostenido predominantemente que cuando en los v. 1076-

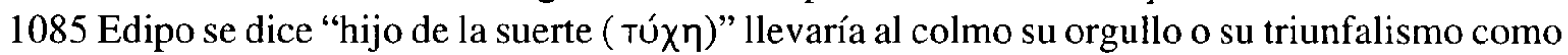
quiere Pohlenz. En cambio Edipo, al igual que Áyax se limita a manifestarse sometido a una fuerza superior que todo lo trastrueca.

Por otra parte la tesis de un Edipo ciego espiritualmente destroza la estructura de la obra, su unidad interna, pues desde Tycho von Wilamowitz está obligada a sostener que de entrada no más, el héroe se olvida de la investigación del crimen y la salvación de Tebas, centrándose en la averiguación de sus ancestros para que la pieza pueda continuar. Recién al final retomaría el tema del comienzo. Con el maligno objeto de humillar a Lessky, a quien acusa de plagiarlo a medias, Egermann cita y comenta quince pasajes donde Edipo insiste en su deseo de salvar a Tebas y descubrir al culpable, lo que sin duda realiza en la acción.

Menos aún resulta tolerable la interpretación de Schadewald quien, siguiendo a Goethe, cree que la esencia de "lo trágico" consiste en que Dios es perverso y bueno a la vez, pero el héroe toma partido por la peor parte dentro del mundo demoníaco. Ocurre en realidad, dice Egermann, que el héroe sofocleo es siempre el aliado de los dioses y sus leyes celestes, en contraposición a la mediocridad cotidiana que se opone al orden divino (p. 105). 
Ante semejante desubicación de los comentaristas modernos, difficile est satura non scribere, y por cierto Egermann ha escrito una impagable sátira filológica que los profesores, sobre todo los más doctos y famosos, ocultan rigurosamente en defensa propia. Su mérito más destacado es haber barrido con los principales errores contemporáneos y habernos devuelto la posibilidad de releer a Sófocles sin el peso de prestigios excesivos. Este labor improbus, destruir a los hermeneutas para recuperar al genio, es nuestra más notable misión y por sí sola justifica la existencia de la crítica.

Para ello Egermann recurrió a la verdadera cultura que le permite reírse de la tecnocracia especializada, volvió al sentido común y a un espíritu de objetividad, que sin duda nace de su confianza en la capacidad de la inteligencia para alcanzar la verdad material y metafísica. Son precisamente las virtudes de Edipo que encontró, por fin, al crítico que necesitaba para no morir sofocado.

\section{Bibliografia}

\section{Textual:}

SCHNEIDEWIN F.W., Oidipus Tyrannus, Berlin: Weidmann, 1981.

KAMERBEEK, J.C., The plays of Sophocles. Edipus Tyrannus, Leiden: Brill, 1967.

\section{Crítica:}

DODDS, E.R., On misunderstanding the CEdipus Rex, Greece and Rome 13, 1966.

EGERMANN, F, Areté und tragische Bewusstheit bei Sophokles und Herodot. München: Bayer, Schulbuchverlag, 1957.

EHRENBERG,V., Sophocles and Pericles. Oxford: London, 1954.

ERRANDONEA, I., Sófocles y su teatro. Madrid: Escelicer, 1962.

JONES, J., Aristotle and the Greek Tragedy. London: Chatto and Windus, 1962.

KITTO, D.H.F., Greek Tragedy, A Literary Study. London: Methuen \& Co LTD, 1939.

KNOX,B., The Heroic Temper. Studies on Sophoclean Tragedy, Univ. of California Press, 1966.

LIDA, M.R., Introducción al Teatro de Sófocles. Bs.As.: Losada, 1944.

MADDALENA, A., Sofocle. Torino: G. Diappichelli Editore, 1963.

O'BRIEN, M.J., Twentieth century interpretation of CEdipus Rex. New Jersey: Prentice Hall,1968.

POHLENZ, M., Die Griechissche Tragödie. Teubner, Leipzig und Berlin, 1930.

REINHARDT,R., Sophokles. Frankfurt am Main, Klostermann, 3 Auflage, 1947.

SCHADEWALDT, W., Sophokles und das Leid, en Hellas und Hesperien. Stuttgart, 1960.

SCHEPPHARD, J.T., The Wisdom of Sophocles, an Essay, by Allen \& Unwin, London, 1947.

SCHLESINGER, E, Edipo Rey. La Plata: Fac. de Humanidades, 1950.

TUROLLA, E, Saggio sulla Poesia de Sofocle. Bari: Laterza,1948.

UNTERSTEINER, M., Sofocle, Studio Critico. Firenze: La Nuova Italia Editrice, 1935. 
WALDOCK, A.J., Sophocles, the dramatist. Cambridge: Cambridge University Press, 1966.

WEINSTOCK, H. Sophokles, Leipzig, 1931.

WILAMOWITZ MÖLLENDORF, Tycho, Die dramatische Tecknik des Sophocles. Zürich: Weismann, 1927

WHITMAN, C. H. Sophocles, a Study of Heroic Humanism. Cambridge: Harvard Univ.Press, 1951.

SEQUEIROS, Octavio A. Les ideologues contre Sophocles. Classica, São Paulo, 7/8: 211-218, $1994 / 1995$.

RÉSUMÉ: L'interprétation de CEdipe Roi résulte aussi contradictoire que les principes, souvent pas franchement avoués, dont chaque professeur part avec la conviction de ce qu'il expose avec "objectivité". Ainsi nous trouvons-nous principalement avec un CEdipe immoral, un autre pantin du destin et un troisième semblant seulement devenir un pure prétexte du jeu esthétique postmoderniste. II y en a des variantes pour tous les goûts. D'abord, je présente historiquement les principales interprétations d'ensemble donnés pendant le $\mathrm{XXe}$ siècle. Puis, j'essaye de démasquer leur fond idéologique et leur coïncidence, sur une plus ou moins grande échelle, avec le texte de Sophocle, auquel reviennent toujours les meilleurs criticiens sur les pas d'Aristote, encore le plus jeune de tous. MOTS CLÉS: Sophocle, CEdipe Roi, interpretations. 